\title{
Clonal spread of an invasive strain of Haemophilus influenzae type $b$ among nursery contacts accompanied by a high carriage rate of non- disease-associated strains
}

\author{
MITSUMASA SAITO*†, KENJI OKADA $\dagger$, KOUICHI TAKEMORI $\$$ and SHIN-ICHI YOSHIDA* \\ Departments of * Bacteriology and $\uparrow$ Paedriatrics, Graduate School of Medical Sciences, Kyushu University and \\ $\$$ Department of Clinical Laboratory, Kyushu University Hospital, Fukuoka 812-8582, Japan
}

\begin{abstract}
Haemophilus influenza carriage was examined in unvaccinated nursery contacts of a patient with $H$. influenzae type b (Hib) meningitis and isolates were typed by pulsedfield gel electrophoresis (PFGE). Nasopharyngeal isolates were classified into eight PFGE patterns. Seven Hib carriers were found among 15 nursery contacts. The isolates from the carriers showed a PFGE pattern identical to that of the meningitis strain. The carrier rate of non-disease-associated strains was also high (47\%, 7 of 15). This study suggests that the clonal spread of invasive (serotype b) $H$. influenzae strains is accompanied by a high carriage rate of non-disease-associated strains.
\end{abstract}

\section{Introduction}

Haemophilus influenzae type $\mathrm{b}$ (Hib) is a common cause of meningitis and other serious infections in children. It has been reported that the Hib colonisation rate among children at day care centres during outbreaks of Hib disease increases significantly [1,2]. It is conceivable that this increase is the result of clonal dissemination, a notion that needs to be confirmed by genetic typing of isolates. An earlier study found that pulsed-field gel electrophoresis (PFGE) analysis was useful in the epidemiological study of $H$. influenzae infection [3]. In October 1996, Hib meningitis occurred in a nursery in Saga City, Japan. The present study determined the rate of carriage of $H$. influenzae among the nursery contacts and analysed the isolates by PFGE. This is the first molecular epidemiological study of Hib carriers and carriers of non-disease-associated $H$. influenzae strains among unvaccinated nursery contracts.

\section{Materials and methods}

Patients

In October 1996, a 3-month-old Japanese female

Received 9 Aug. 1999; revised version accepted 8 Feb. 2000.

Corresponding author: Dr M. Saito (email: msaito@bact. med.kyushu-u.ac.jp). infant was hospitalised because of fever and vomiting. She had been in a nursery in Saga City, Japan, since birth. H. influenzae was isolated from her cerebrospinal fluid (CSF) and she was diagnosed as having purulent meningitis. The isolate was serotyped as type $\mathrm{b}$ and biotyped as type I according to the methods described below. Antibiotic therapy led to a successful recovery.

A total of 16 children, including the patient with Hib meningitis, had lived together in the nursery. These children had left their parental care, for family reasons and received around the clock nursing care. None of the children had received Hib vaccine. Nasopharyngeal swabs were taken from all nursery contacts (15 children) just after the meningitis patient was hospitalised. Their ages ranged from 2 to 23 months (Table 1).

\section{Microbiology}

Swabs were streaked on the selective medium (Haemophilus chocolate agar; bioMérieux-Vitek, Lyon, France) which was supplemented with bacitracin to inhibit the growth of bacteria other than the Haemophilus group. For primary cultures, plates were incubated at $37^{\circ} \mathrm{C}$ overnight. Eight colonies were picked from primary cultures plates and subcultured on a fresh chocolate agar plate for further analysis. Serotyping, biotyping and PFGE typing were performed by methods described previously [3]. 
Table 1. Isolation of $H$. influenzae strains from a meningitis patient and her 15 nursery contacts at two different times

\begin{tabular}{|c|c|c|c|c|c|c|c|}
\hline Subject & & $\begin{array}{c}\text { Age } \\
\text { (months) }\end{array}$ & Sex & $\begin{array}{l}\text { Length of stay } \\
\text { in the nursery } \\
\text { (months) }\end{array}$ & $\begin{array}{l}\text { Isolation of } \\
\text { H. influenzae } \\
\text { (Feb. 1996) }\end{array}$ & $\begin{array}{l}\text { Isolation of } \\
\text { H. influenzae } \\
\text { (Oct. 1996) }\end{array}$ & $\begin{array}{l}\text { PFGE patterns } \\
\text { (serotype) } \\
\text { (Oct. 1996) }\end{array}$ \\
\hline Patient & & 3 & $\mathrm{~F}$ & 3 & $\ldots$ & + & $\mathrm{D}(\mathrm{b})$ \\
\hline \multirow[t]{15}{*}{ Nursery contact } & 1 & 23 & M & 21 & - & + & $\mathrm{C}(\mathrm{a}), \mathrm{F}(\mathrm{NT})$ \\
\hline & 2 & 23 & $\mathrm{~F}$ & 19 & - & - & $\ldots$ \\
\hline & 3 & 15 & $\mathrm{M}$ & 15 & + & - & $\cdots$ \\
\hline & 4 & 20 & M & 14 & - & + & $\mathrm{D}_{1}(\mathrm{~b}), \mathrm{D}_{2}(\mathrm{~b}), \mathrm{E}(\mathrm{NT})$ \\
\hline & 5 & 14 & M & 13 & - & + & $D_{1}$ (b) \\
\hline & 6 & 12 & $\mathrm{~F}$ & 11 & - & + & $\mathrm{C}(\mathrm{a}), \mathrm{F}(\mathrm{NT})$ \\
\hline & 7 & 20 & M & 10 & - & + & $\mathrm{F}(\mathrm{NT})$ \\
\hline & 8 & 11 & $\mathrm{M}$ & 10 & - & + & $D_{1}(b)$ \\
\hline & 9 & 9 & $\mathrm{~F}$ & 9 & - & + & $\mathrm{D}_{1}$ (b), G (NT) \\
\hline & 10 & 9 & $\mathrm{~F}$ & 8 & - & + & $\mathrm{D}_{1}$ (b), G (NT) \\
\hline & 11 & 6 & $\mathrm{~F}$ & 5 & $\ldots$ & + & $\mathrm{A}(\mathrm{a}), \mathrm{B}(\mathrm{a})$ \\
\hline & 12 & 4 & $\mathrm{~F}$ & 4 & $\cdots$ & - & $\ldots$ \\
\hline & 13 & 4 & M & 3 & $\ldots$ & + & $\mathrm{D}_{1}(\mathrm{~b}), \mathrm{D}_{2}(\mathrm{~b})$ \\
\hline & 14 & 9 & M & 3 & $\ldots$ & + & $\mathrm{D}_{1}$ (b) \\
\hline & 15 & 2 & $\mathrm{~F}$ & 1 & $\ldots$ & - & $\ldots$ \\
\hline
\end{tabular}

M, male; F, female; NT, non-typable; ..., not tested.

\section{Results}

Immediately after the patient with Hib meningitis was hospitalised, the nasopharyngeal carriage of $H$. influenzae among the other nursery children was investigated. Eight months before this contact tracing (in Feb. 1996), nasopharyngeal samples had been taken from the nursery children for a different reason. The results of the investigations pre- and post-disease occurrence are shown in Table 1. Before identification of the index case, one (10\%) of 10 children was found to be colonised with $H$. influenzae. However, on contact screening, $11(73 \%)$ of 15 children carried $H$. influenzae. The initial carrier (nursery contact 3) had become negative on this occasion.

\section{Subtyping}

Capsular type $\mathrm{b}$ strains were carried by the majority of H. influenzae-positive contacts (7 of 11). A total of eight PFGE patterns were distinguished among the $H$. influenzae strains examined in this study; these were labelled $\mathrm{A}-\mathrm{G}$ (Fig. 1). As differences between patterns $D_{1}$ and $D_{2}$ consisted of only one extra band in pattern

PFGE patterns

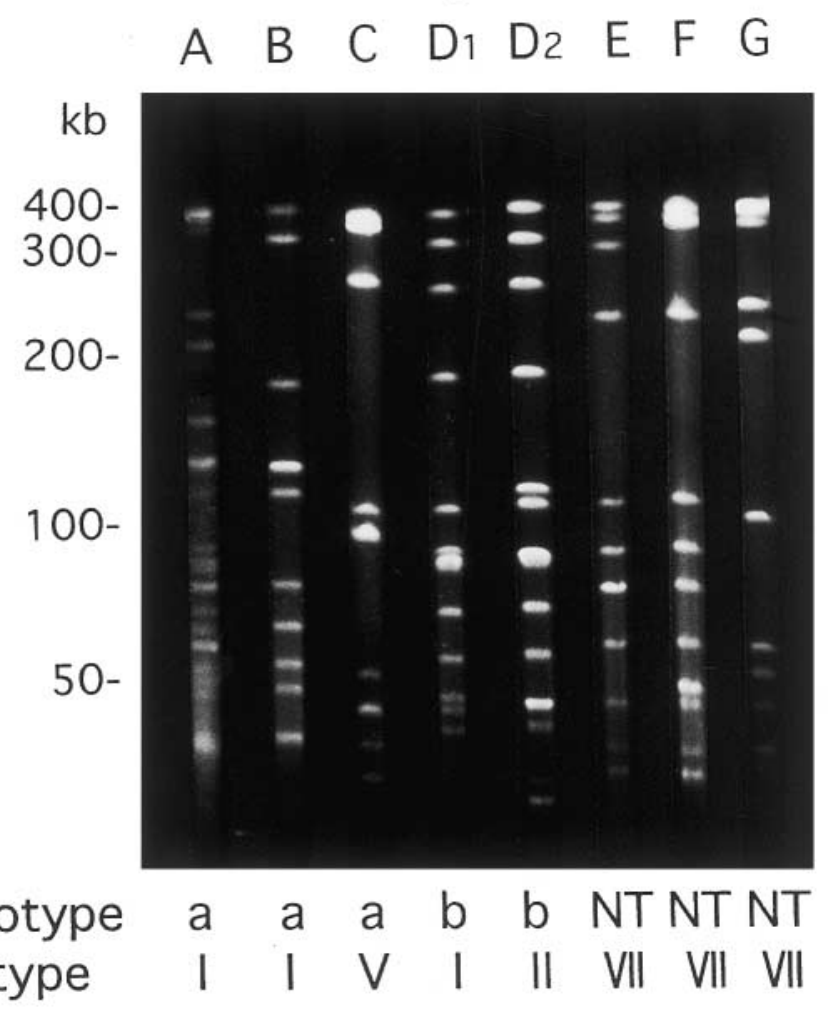

Fig. 1. Eight PFGE patterns $(\mathrm{A}-\mathrm{G})$ of $H$. influenzae isolates. The serotypes and biotypes of each pattern are shown under each lane. NT, non-typable. 
$\mathrm{D}_{2}$, these isolates were considered to be genetically related [4]. The PFGE pattern of the patient's strain was pattern $D_{1}$ and the majority of isolates from nursery contact nos. 4, 5, 8, 9, 10, 13 and 14 had an indistinguishable pattern (Table 2). Moreover, contacts $1,6,7$ and 11 harboured strains that were clearly different from the invasive strain of the index case. More than one PFGE pattern was identified among isolates from each of the contacts $1,4,6,9,10$ and 11 .

\section{Discussion}

Population-based studies have shown that children who attend day care centres are at a significantly higher risk for invasive Hib disease than children who do not [57]. One study estimated that up to $50 \%$ of all invasive Hib diseases may be attributable to day-care attendance [5].

Previous studies have shown that the carriage rates of $\mathrm{Hib}$ in children at day-care centres during Hib disease occurrence were $49 \%$ [1] and $23-56 \%$ [2], while disease-free periods are characterised by lower carriage rates of about $1 \%$ [1]. Other studies have reported that Hib is carried in the nasopharynx of $0.5-3 \%$ of healthy children aged $<24$ months [8-10]. The present finding that the rate of carriage of Hib in contacts of patients is c. 15-100 times higher than the rate in other children in the same age group is in close agreement with previous reports $[1,2]$.

The seven Hib carriers in this study had strains in their nasopharynges that showed the same PFGE pattern as that of the isolate from the CSF of the patient with Hib meningitis. This finding suggested that the invasive Hib strain had spread widely among the nursery contacts. It

Table 2. PFGE patterns and the distribution of the eight $H$. influenzae strains isolated from each nursery contact

\begin{tabular}{|c|c|c|c|c|c|c|c|c|}
\hline \multirow[b]{2}{*}{ Nursery contact no. } & \multicolumn{8}{|c|}{$\begin{array}{c}\text { Numbers of } H \text {. influenzae colonies }{ }^{\dagger} \\
\text { showing PFGE patterns }\end{array}$} \\
\hline & A & B & $\mathrm{C}$ & $\mathrm{D}_{1}^{*}$ & $\mathrm{D}_{2}$ & $\mathrm{E}$ & $\mathrm{F}$ & G \\
\hline 1 & & & 5 & & & & 3 & \\
\hline 4 & & & & 4 & 1 & 3 & & \\
\hline 5 & & & & 8 & & & & \\
\hline 6 & & & 4 & & & & 4 & \\
\hline 7 & & & & & & & 8 & \\
\hline 8 & & & & 8 & & & & \\
\hline 9 & & & & 7 & & & & 1 \\
\hline 10 & & & & 6 & & & & 2 \\
\hline 11 & 1 & 7 & & & & & & \\
\hline 13 & & & & 5 & 3 & & & \\
\hline 14 & & & & 8 & & & & \\
\hline
\end{tabular}

* The same pattern as the strain which caused meningitis.

${ }^{\dagger}$ A total of eight colonies obtained from nasopharyngeal cultures and used for PFGE analysis. was not possible to examine whether the nursery workers carried the patient's strain or not. However, it is possible that the staff transmitted Hib bacteria to susceptible children in the nursery.

In this study, the carriage rate of the non-diseaseassociated strains (PFGE patterns A, B, C, E, F and G) was $47 \%$ (7 of 15 ). It was noteworthy that not only the number of carriers of the invasive (serotype b) $H$. influenzae strains, but also that of the non-invasive strains had increased among the nursery contacts. It can be speculated that certain conditions favour the spread of $H$. influenzae regardless of their invasiveness. Further studies are necessary to elucidate such environmental and host factors.

Furthermore, PFGE analysis revealed that seven $H$. influenzae carriers had two or three strains with different PFGE patterns in their nasopharynx. This result suggests that more than one strain of $H$. influenzae often colonises the individual nasopharynx.

It can be conclued that clonal dissemination of more than one strain of $H$. influenzae precedes the occurrence of invasive disease in institutions where children were nursed in close proximity.

We thank A. Umeda and K. Amako for helpful discussion and advice and Mrs Linda Saza for her valuable editorial advice on the manuscript.

\section{References}

1. Granoff D, Gilsdorf J, Gessert C, Basden M. Haemophilus influenzae type $\mathrm{b}$ disease in a day care center: eradication of carrier state by rifampin. Pediatrics 1979; 63: 397-401.

2. Ginsburg CM, McCracken GH, Rae S, Parke JC. Haemophilus influenzae type $\mathrm{b}$ disease. Incidence in a day-care center. JAMA 1977; 238: 604-607.

3. Saito M, Umeda A, Yoshida S-I. Subtyping of Haemophilus influenzae strains by pulsed-field gel electrophoresis. J Clin Microbial 1999; 37: 2142-2147.

4. Tenover FC, Arbeit RD, Goering RV et al. Interpreting chromosomal DNA restriction patterns produced by pulsedfield gel electrophoresis: criteria for bacterial strain typing. J Clin Microbiol 1995; 33: 2233-2239.

5. Cochi SL, Fleming DW, Hightower AW et al. Primary invasive Haemophilus influenzae type $\mathrm{b}$ disease: a population-based assessment of risk factors. J Pediatr 1986; 108: 887-896.

6. Istre GR, Conner JS, Broome CV, Hightower A, Hopkins RS. Risk factors for primary invasive Haemophilus influenzae disease: increased risk from day care attendance and schoolaged household members. J Pediatr 1985; 106: 190-195.

7. Redmond SR, Pichichero ME. Haemophilus influenzae type b disease: an epidemiologic study with special reference to daycare centers. JAMA 1984; 252: 2581-2584.

8. Howard AJ, Dunkin KT, Millar GW. Nasopharyngeal carriage and antibiotic resistance of Haemophilus influenzae in healthy children. Epidemiol Infect 1988; 100: 193-203.

9. Michaels RH, Pozviak CS, Stonebaker FE, Norden CW. Factors affecting pharyngeal Haemophilus influenzae type b colonization rates in children. J Clin Microbiol 1976; 4: 413-417.

10. Asahi E, Okada K, Ueda K. [Nasopharyngeal flora and carriage rates of Haemophilus influenzae type b of healthy infants.] Kansenshogaku Zasshi 1997; 71: 236-240. 